OPEN ACCESS

Edited by:

Stephen Seiler,

University of Agder, Norway

Reviewed by:

Hugo A. Kerhervé,

University of Rennes 2 - Upper

Brittany, France

Arja L. T. Uusitalo,

Helsinki University Central Hospital,

Finland

${ }^{*}$ Correspondence:

Nicki Winfield Almquist

nicki.almquist@inn.no

Specialty section:

This article was submitted to

Exercise Physiology,

a section of the journal

Frontiers in Physiology

Received: 16 December 2021

Accepted: 28 January 2022

Published: 01 March 2022

Citation:

Almquist NW, Eriksen HB, Wilhelmsen $M$, Hamarsland $H$, Ing $S$,

Ellefsen S, Sandbakk Ø,

Rønnestad BR and

Skovereng K (2022) No Differences Between 12 Weeks of Block- vs.

Traditional-Periodized Training in

Performance Adaptations in Trained

Cyclists.

Front. Physiol. 13:837634

doi: 10.3389/fphys.2022.837634

\section{No Differences Between 12 Weeks of Block- vs. Traditional-Periodized Training in Performance Adaptations in Trained Cyclists}

\author{
Nicki Winfield Almquist,2*, Hanne Berg Eriksen ${ }^{1}$, Malene Wilhelmsen ${ }^{1}$, \\ Håvard Hamarsland' ${ }^{1}$, Steven Ing' ${ }^{2}$, Stian Ellefsen', Øyvind Sandbakk' ${ }^{2}$, Bent R. Rønnestad' \\ and Knut Skovereng ${ }^{2}$

\footnotetext{
Section for Health and Exercise Physiology, Inland Norway University of Applied Sciences, Lillehammer, Norway, ${ }^{2}$ Centre for Elite Sports Research, Department of Neuromedicine and Movement Science, Norwegian University of Science and Technology, Trondheim, Norway
}

The purpose of this study was to compare the effects of 12 weeks load-matched block periodization (BP, $n=14)$, using weekly concentration of high- (HIT), moderate- (MIT), and low- (LIT) intensity training, with traditional periodization (TP, $n=16$ ) using a weekly, cyclic progressive increase in training load of HIT-, MIT-, and LIT-sessions in trained cyclists (peak oxygen uptake: $58 \pm 8 \mathrm{ml} \cdot \mathrm{kg}^{-1} \cdot \mathrm{min}^{-1}$ ). Red blood cell volume increased $10 \pm 16 \%$ $(p=0.029)$ more in BP compared to TP, while capillaries around type I fibers increased $20 \pm 12 \%(p=0.002)$ more in TP compared to BP from Pre to Post12. No other group differences were found in time-trial $(T T)$ performances or muscular-, or hematological adaptations. However, both groups improved 5 and 40 -min $\pi$ power by $9 \pm 9 \%(p<0.001)$ and $8 \pm 9 \%(p<0.001)$, maximal aerobic power $\left(W_{\max }\right)$ and power output $(\mathrm{PO})$ at $4 \mathrm{mmo} \cdot \mathrm{L}^{-1}$ blood lactate $\left(W_{4 \mathrm{mmol}}\right)$, by $6 \pm 7(p=0.001)$ and $10 \pm 12 \%(p=0.001)$, and gross efficiency (GE) in a semi-fatigued state by $0.5 \pm 1.1 \%$-points $(p=0.026)$. In contrast, GE in fresh state and $\mathrm{VO}_{2 \text { peak }}$ were unaltered in both groups. The muscle protein content of $\beta$-hydroxyacyl (HAD) increased by $55 \pm 58 \%$ in TP only, while both TP and BP increased the content of cytochrome c oxidase subunit IV (COXIV) by $72 \pm 34 \%$. Muscle enzyme activities of citrate synthase (CS) and phosphofructokinase (PFK) were unaltered. TP increased capillary-tofiber ratio and capillary around fiber (CAF) type I by $36 \pm 15 \%(p<0.001)$ and $17 \pm 8 \%$ $(p=0.025)$, respectively, while BP increased capillary density $(C D)$ by $28 \pm 24 \%(p=0.048)$ from Pre to Post12. The present study shows no difference in performance between BP and "best practice"-TP of endurance training intensities using a cyclic, progressively increasing training load in trained cyclists. However, hematological and muscle capillary adaptations may differ.

Keywords: periodization, best practice, endurance training, skeletal muscle measures, hematological measures 


\section{INTRODUCTION}

Block periodization (BP) is a popular method for training organization used among coaches for elite athletes since the 1970's (Issurin, 2010), and with scientific evidence for its effectiveness steadily accumulating. The main identifying factor of $\mathrm{BP}$ is a prioritized development of specific abilities in succession to avoid possibly conflicting stimuli by targeting specific stimuli in the blocked periods, thus contrasting traditional periodization (TP; Issurin, 2019).

A recent meta-analysis, summarizing the literature, demonstrated a small benefit of utilizing BP compared to TP of intervals on both maximal oxygen uptake $\left(\mathrm{VO}_{2 \max }\right)$ and maximal aerobic power ( $\mathrm{W}_{\max }$; Molmen et al., 2019). Furthermore, this meta-analysis highlighted that the results diverged between studies, which may relate to small numbers of participants and generally low methodological quality. However, the divergence in results between studies applying a $\mathrm{BP}$ or $\mathrm{TP}$ might also reflect differences in content-, and distribution of training at different intensities (low-, moderate-, high-intensity training; LIT, MIT, and HIT, respectively), age, sex, and performance-level.

A cyclic, progressive increase in training load is a common feature of periodized training programs (Mujika et al., 2018), i.e., a progressive increase in duration, intensity, or the number of intervals. Even though this is viewed as a "best practice" approach, it is still a less stressed feature in studies comparing BT and TP. That being said, it has also been reported that it is "best practice" to use a polarized approach applying only LIT and HIT (Seiler, 2010). In line with the latter most BP vs. TP studies have focused on LIT and HIT, while MIT is almost excluded (Ronnestad et al., 2012, 2014, 2016; McGawley et al., 2017). Although HIT is shown to be superior to MIT only in improving $\mathrm{VO}_{2 \max }$ and $\mathrm{W}_{\max }$ (Stoggl and Sperlich, 2014), it can be argued that MIT is an natural part of an welldesigned endurance training schedule of endurance-trained individuals (Jones, 2006; Solli et al., 2019; van Erp et al., 2019). The inclusion of MIT could, arguably, be beneficial for improvements in performance at submaximal work rates.

On the molecular level, differentiating training stimuli might hypothetically help avoid stagnation in muscular adaptations (Goutianos, 2016). Indeed, mRNA-responses of the "masterswitch" of mitochondrial adaptations, peroxisome proliferatoractivated receptor $\gamma$ co-activator- $1 \alpha(\mathrm{PGC} 1 \alpha)$, have been reported gradually blunted (7-fold vs. 2-fold) when untrained subjects repeated the same endurance exercise session over time (Perry et al., 2010; Granata et al., 2019). Based on the above, it can be suggested that weekly changes in training focus and loads, induced by BP can induce greater molecular adaptations than the less weekly changes in a traditional evenly loaded TP. However, the molecular responses to $\mathrm{BP}$ and a TP with cyclic progressive increases in training load are thus far scarcely investigated (Goutianos, 2016).

However, whether the reported small beneficial effects of BP are mainly an effect of the change from a monotonous TP to a concentrated focus of BP or whether the results would be different by including MIT in both periodization approach is unclear. Hence, the effects of periodizing the major endurance intensity-modalities (i.e., HIT, MIT, and LIT) in a blocked periodization compared with a "best practice" TP, with cyclic, progressive loads using LIT, MIT, and HIT sessions has not yet been investigated. Also, the majority of studies finding no or only small differences between $\mathrm{BP}$ and $\mathrm{TP}$ in performancerelated outcomes are of short duration (1-5 weeks; Breil et al., 2010; Clark et al., 2014; Ronnestad et al., 2016; McGawley et al., 2017), and it cannot be excluded that a longer duration might accentuate a possible difference in responses to BP and TP.

Therefore, the purpose of this study was to compare loadmatched BP, using concentrated HIT-, MIT-, and LIT-weeks, with a TP using a mix of HIT-, MIT-, and LIT-sessions with a cyclic progressive increase in training load over 4 and 12 weeks in trained cyclists.

\section{MATERIALS AND METHODS}

\section{Participants}

The current 12-week multi-center study involved two test-centers both completing a training intervention mid-winter (January-March) comparing BP with TP in a training load-matched parallel-group design. Participants were recruited from local cycling clubs near each test center. Fifteen cyclists participated at each test-centers, including four females and 26 males. All participants were categorized as trained with seven subjects at performance level 2, 14 participants at level 3, and seven at level 4-5 (De Pauw et al., 2013). Participants' characteristics are shown in Table 1. The study was pre-registered with the Norwegian Social Science Data Services (NSD\#: 61042), approved by the local ethical committee at Lillehammer University College, and performed according to the Declaration of Helsinki. All subjects were informed of the possible risks and discomforts associated with the study and provided their written informed consent before study participation.

\section{Screening and Experimental Design}

Before being included in the study, subjects performed a 40-min TT on their own bike, mounted on a bike trainer (Tacx Neo Smart, NL or Computrainer, Racermate, Seattle, United States). Heart rate $(\mathrm{HR})$ and power output $(\mathrm{PO})$ were recorded throughout, and blood lactate $\left[\mathrm{BLa}^{-}\right]$and rate of perceived exertion (RPE) were recorded every $5 \mathrm{~min}$. Based on the average PO of a 40-min TT screening test and sex, the participants were pair-matched and randomly assigned to either BP or TP. After the physiological testing on test day 1 and 2 (see section "Testing procedures") the participants completed three mesocycles of 4 weeks duration of either BP or TP (Figure 1). After the first meso-cycle a blood lactate profile test, a 6-s all-out sprint test, and a $\mathrm{VO}_{2 \text { peak }}$ test were performed (Post4), while after the 12-week intervention, test days 1 and 2 were repeated (Post12).

\section{Intervention, Training Load, and Adherence}

For the BP group, the 4-week mesocycle consisted of four MIT sessions in week 1, three LIT sessions in week 2, and 
TABLE 1 | Participant's characteristics and training volume.

\begin{tabular}{|c|c|c|c|c|c|}
\hline & \multicolumn{2}{|c|}{ TP } & \multicolumn{2}{|c|}{ BP } & \multirow[b]{2}{*}{ BP vs. TP } \\
\hline & Men $(n=14)$ & Women $(n=2)$ & Men $(n=12)$ & Women $(n=2)$ & \\
\hline Age $(Y)$ & $35.5 \pm 12.8$ & $34.4 \pm 4.9$ & $40.5 \pm 12.0$ & $42.0 \pm 6.6$ & $p=0.156$ \\
\hline Body mass (kg) & $83.9 \pm 23.6$ & $66.7 \pm 8.1$ & $79.9 \pm 8.2$ & $65.6 \pm 0.2$ & $p=0.299$ \\
\hline $\mathrm{W}_{4 \mathrm{mmol}}(\mathrm{W})$ & $3.2 \pm 0.6$ & $2.6 \pm 0.8$ & $3.2 \pm 0.6$ & $2.6 \pm 0.2$ & $p=0.878$ \\
\hline $\mathrm{VO}_{2 \text { peak }}\left(\mathrm{ml} \cdot \mathrm{kg}^{-1} \cdot \mathrm{min}^{-1}\right)$ & $59.4 \pm 17.3$ & $51.9 \pm 5.7$ & $57.1 \pm 7.1$ & $51.0 \pm 5.5$ & $p=0.428$ \\
\hline $\mathrm{W}_{\max }\left(\mathrm{W} \cdot \mathrm{kg}^{-1}\right)$ & $5.1 \pm 1.5$ & $3.9 \pm 1.2$ & $5.0 \pm 0.8$ & $4.1 \pm 0.7$ & $p=0.836$ \\
\hline 40-min TT $\left(\mathrm{W} \cdot \mathrm{kg}^{-1}\right)$ & $3.3 \pm 0.5$ & $2.6 \pm 0.2$ & $3.4 \pm 0.5$ & $2.6 \pm 0.4$ & $p=0.832$ \\
\hline $\begin{array}{l}\text { Training volume } \\
\text { (hours.wk.-1) }\end{array}$ & $6.7 \pm 3.6$ & $3.7 \pm 3.0$ & $6.9 \pm 3.5$ & $7.3 \pm 1.4$ & $p=0.590$ \\
\hline
\end{tabular}

$W_{4 m m o l}(W)$, power output at $4 \mathrm{mmol} \cdot \mathrm{L}^{-1}$ blood lactate concentration; $\mathrm{VO}_{2 \text { peak, }}$ peak oxygen uptake; $W_{\text {max }}$ maximal aerobic power output during the last minute of an incremental test to exhaustion; TT, time trial; and TV, training volume the month prior to inclusion in study (hours. $w k^{-1}{ }^{-1}$.

four HIT sessions in week 3. For the TP group, the mesocycle consisted of alternating HIT, MIT, and LIT sessions evenly distributed throughout the first 3 weeks. The 4 th week of each mesocycle was prescribed as a recovery week for both groups. Both groups were prescribed the same total number of HIT, MIT, and LIT sessions during each 4-week mesocycle and the HIT and MIT were made up of the same total number of efforts and had the same total duration. The recovery weeks were used as a catch-up for those who did not complete all MIT/HIT-sessions in the designated week. The Post12 test was performed on average $4 \pm 2$ days after the last MIT/HIT-session.

The participants were required to perform a minimum of four interval sessions (i.e., two MIT and two HIT) under the supervision of test leaders from the test centers, and they had the option for performing all HIT and MIT sessions under supervision. The supervised training was performed at the same location as all performance testing. Training was performed on personal bikes mounted on the same trainer throughout the study provided by the test centers. All LIT training was performed unsupervised, and other training forms such as $\mathrm{XC}$-skiing and running were allowed only as LIT-sessions.

The HIT and MIT training were carried out as five efforts of $5 \mathrm{~min}$ and four efforts of $12 \mathrm{~min}$, respectively, for the $\mathrm{BP}$ group. The TP group included a degree of progression in the sessions through each mesocycle and completed four, five, and six efforts for the three first HIT sessions and three, four, and five efforts for the three first MIT sessions. The last HIT and MIT session was identical between both groups to ensure that the last HIT stimulus was similar before recovery week and post-testing. All sessions were carried out using an effort-based approach. The participants were instructed to perform all sessions at the highest possible average power output without reducing the power output after the first effort. Target RPE scores for each session type with gradually increasing effort for each interval (i.e., MIT: 14-18 and HIT: 16-19) were provided as a guideline.

One male participant in the BP group dropped out due to the high training load. All participants completed the intervention but three male participants (two in the BP group and one in the TP group) were excluded from the final analysis due to insufficient compliance to the training intervention [i.e., too few completed sessions $(<85 \%)$ or due to the completion of the block periods over too many days $(>6)]$.

\section{Training Load Quantification}

The training was registered in a commercially available online training diary (trainingpeaks.com, Colorado, United States). The participants were required to register all training (i.e., HIT, MIT, LIT, and strength training and activity mode) during the entire intervention period. Training load was quantified using the iTRIMP as described elsewhere (Manzi et al., 2009), by weighting exercise intensity according to an individual's own HR vs. $\left[\mathrm{Bla}^{-}\right]$relationship, calculated by the line of best fit from the lactate profile and $\mathrm{VO}_{2 \text { peak }}$ test. iTRIMP uses the weighting factor $y_{i}$, which increases exponentially based on the $\mathrm{HR}$ vs. $\left[\mathrm{Bla}^{-}\right]$relationship to weight every $\mathrm{HR}$. An accumulated iTRIMP score was calculated by the following equation:

$$
\text { iTRIMP }[\operatorname{arbitrary} \text { units }(\mathrm{AU})]=\mathrm{D}(\min ) \times \Delta H R_{\text {ratio }} \times \text { yi }
$$

where $\Delta H R_{\text {ratio }}$ is calculated from $\left(\mathrm{HR}_{\text {work }}-\mathrm{HR}_{\text {rest }}\right) /\left(\mathrm{HR}_{\max }-\mathrm{HR}_{\text {rest }}\right)$, and $D$ is time spent exercising.

\section{Training}

The average adherence to the training for the participants included in the final analysis was $92 \pm 8 \%$. Data from 12 (i.e., six HIT and six MIT) of the supervised sessions showed an expected effect of session design, with greater power output during the HIT sessions compared to the MIT sessions $(p<0.01)$, also reflected by a higher $\left[\mathrm{Bla}^{-}\right](p<0.01)$. However, the average session RPE was not different between the supervised HIT and MIT sessions $(p=0.760)$.

The average weekly training volume (hrs.wk. ${ }^{-1}$ ) during the intervention was not different between groups $(p=0.571)$ with an average of $7.5 \pm 2.0 \mathrm{~h} \cdot \mathrm{wk}^{-1}$ in TP and $8.0 \pm 2.7 \mathrm{~h} \cdot \mathrm{wk} .^{-1}$ in $\mathrm{BP}$, respectively. Hence, the increase in training volume from habitual training was not different between groups $(p=0.938)$ with an increase of $43 \pm 89 \%$ in TP and $46 \pm 125 \%$ in BP.

The training load (i.e., iTRIMP scores) for the whole intervention period was not different between the groups $(p=0.820)$ and there was no difference in the average iTRIMP score from 


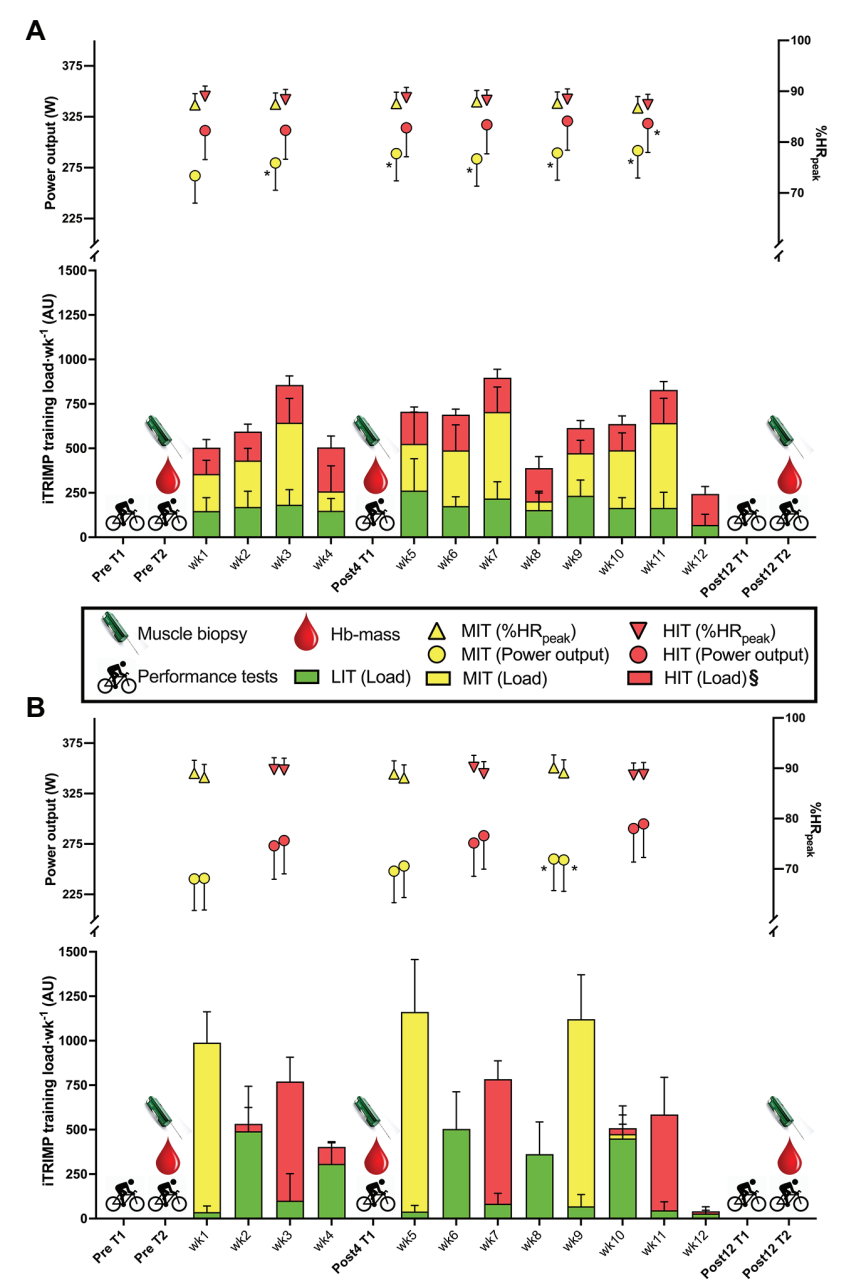

FIGURE 1 | Experimental design and training load (iTRIMP) during a 4-week (Post4) and 12-week (Post12) intervention of either traditional periodization (TP, panel A) or blocked periodization (BP, panel B) of endurance training among 26 trained cyclists. Test day 1 (T1) included a blood lactate profile test, a peak oxygen uptake $\left(\mathrm{NO}_{2 \text { peak }}\right.$-test and a 5-min time-trial (TT) performance test. Test day 2 (T2) included muscle biopsies, a 40-min $\Pi \mathrm{T}$ and measurement of hemoglobin mass. Mean power output (PO) and \% of peak heart rate (\%HR peak) on the first and last moderate intensity training (MIT)- and high intensity training (HIT)-exercises of each mesocycle of 4 weeks are presented above the training load. Data are mean $\pm 95 \% \mathrm{Cl}$. *Indicates a significant difference from the first MIT or HIT exercise $(p<0.05)$. $\S$ indicates a significant difference in HIT-load between TP and BP $(p<0.05)$. LIT, low-intensity training; MIT, moderate-intensity training; HIT, high-intensity training; $\mathrm{Hb}$-mass, hemoglobin mass; and iTRIMP, individualized training impulse.

the LIT and MIT sessions (both $p>0.54$; Figure 1). The BP group had a higher iTRIMP score in the HIT sessions $(p>0.05)$, which was reflected by a higher session-RPE compared to the TP group $(p<0.05)$, whereas no difference in session-RPE was observed for MIT sessions $(p=0.07)$. Time spent in the five heart rate zones, as defined by Seiler (2010), over the whole study was not different between BP and TP (all $p>0.09$ ), and there was no difference between $\mathrm{BP}$ and TP in $\left[\mathrm{Bla}^{-}\right](p=0.47)$.

Power output during MIT and HIT sessions increased from the beginning to the end of the intervention period in both groups $(p<0.05)$ and both the increase during the intervention period $(p=0.64)$ and the difference in power output between the MIT and HIT sessions $(p=0.96)$ did not differ between the groups. Across groups there was a tendency for $\left[\mathrm{Bla}^{-}\right]$to decrease during the intervention period $(p=0.06)$, whereas RPE $(p=0.29)$ did not change.

\section{Testing Procedures}

The day prior to each experimental day of testing, the participants were instructed to perform a standardized, self-organized 1-h LIT-session.

\section{Test Day 1 (T1): Physiological Tests \\ Blood Lactate Profile Test}

The blood lactate profile test has previously been described (Almquist et al., 2020) and consisted of 5-min stages with incremental load $(50 \mathrm{~W})$. When the participants reached a blood lactate of $3 \mathrm{mmol} \cdot \mathrm{L}^{-1}$, the load increases were reduced to $25 \mathrm{~W}$. The blood lactate profile was terminated when blood lactate exceeded $4 \mathrm{mmol} \cdot \mathrm{L}^{-1} \cdot \mathrm{VO}_{2}$ measurements started from $2 \mathrm{~min}$ into every bout and $\mathrm{VO}_{2}$ was calculated as an average from 2.5 to $4.5 \mathrm{~min}$ and blood was sampled from the fingertip on completion of each 5-min bout and analyzed 
for whole blood $\left[\mathrm{La}^{-}\right]$using a lactate analyzer (Biosen C line, EKF Diagnostic, Germany). HR was recorded using the participants' own HR-monitor and RPE was recorded according to Borg Scale 6-20. $\mathrm{VO}_{2}$ was measured using a computerized metabolic system with a mixing chamber (Oxycon Pro, Erich Jaeger, Hoechberg, Germany), which was calibrated every hour and all cycling was performed on an electromagnetic braked cycle ergometer (Lode Excalibur Sport, Lode B. V., Groningen, The Netherlands) which was adjusted to each cyclists' individual preferences and replicated throughout all testing.

\section{6-s All-Out Sprint}

After a 5-min active recovery a 6-s all-out sprint test was performed in the seated position using the Wingate modus with a stationary start and a resistance of $0.8 \mathrm{Nm} \cdot \mathrm{kg}^{-1}$ body mass. Peak power output was defined as the highest value achieved during the 6-s all-out, with recordings at $5 \mathrm{~Hz}$.

\section{$V O_{\text {2peak }}$ Test}

Following another 5-min active recovery, a $\mathrm{VO}_{2 \text { peak }}$ test was performed. The test was performed using an incremental ramp protocol with $25 \mathrm{~W}$ increments each minute until voluntary exhaustion or the inability to maintain a cadence $>60 \mathrm{rpm}$. The starting work rate was individually adjusted based on the lactate profile test to ensure exhaustion in 8-12 min. $\mathrm{VO}_{2 \text { peak }}$ was calculated as the highest average of a 1-min moving average using 5-s $\mathrm{VO}_{2}$-measurements and peak heart rate $\left(\mathrm{HR}_{\text {peak }}\right)$ was registered. $\mathrm{W}_{\max }$ was calculated as the mean power output during the last minute of the incremental test.

\section{5 min Continuous Cycling and 5-min TT}

After $10 \mathrm{~min}$ of active recovery the participants cycled for $30 \mathrm{~min}$ at an intensity corresponding to $60 \%$ of $\mathrm{VO}_{2 \text { peak }}$ after which the third-last and second-last stages from the blood lactate profile test were repeated followed by another $5 \mathrm{~min}$ at $60 \%$ of $\mathrm{VO}_{2 \text { peak. }}$. This was immediately followed by a 5 -min self-paced TT, where the participants were instructed to achieve the highest possible mean power output. The start power output was replicated at Post to ensure the same pacing conditions. $\mathrm{VO}_{2}, \mathrm{HR}, \mathrm{RPE}$, and $\left[\mathrm{Bla}^{-}\right]$were measured during the repeated stages from the blood lactate profile test and during the 5-min TT. $\mathrm{VO}_{2}$-measurements started 30 -s prior to each period to ensure steady measures of $\mathrm{VO}_{2}$. Water, energy-drink (HIGH-5, United Kingdom), and gels (SIS Isotonic Energy Gel, United Kingdom) without caffeine were provided ad libitum after the incremental test to exhaustion and throughout the test. The amount was recorded and repeated at Post12 to ensure the same relative hydration level. Gross efficiency (GE) was defined as the ratio between the mechanical PO and the metabolic power input (PI) calculated using $\mathrm{VO}_{2}$ measurements and the energetic equivalent (Peronnet and Massicotte, 1991) $\mathrm{PI}=\mathrm{VO}_{2} \quad \mathrm{~L} \cdot \mathrm{s}^{-1} \times\left(4,840 \mathrm{~J} \cdot \mathrm{L}^{-1} \times \mathrm{RER}+16,890 \mathrm{~J} \cdot \mathrm{L}^{-1}\right) . \quad \mathrm{GE} \quad$ was calculated from the blood lactate profile test in the fresh state and from the two repeated stages in the fatiguing state during $45 \mathrm{~min}$ continuous cycling.
Test Day 2 (T2): Muscle Sampling and 40-min TT The participants arrived at the laboratory at least $2 \mathrm{~h}$ after the last, standardized meal and rested for $20 \mathrm{~min}$ in a supine position. Two muscle biopsies were collected, using the microbiopsy technique as described elsewhere (Hayot et al., 2005) with a 14-gauge needle (Bard Magnum, Bard Nordic, Helsingør, Denmark) in the resting state under local anesthesia (Xylocaine, $10 \mathrm{mg} \cdot \mathrm{ml}^{-1}$, AstraZenaca AS, Oslo, Norway) from the m. Vastus Lateralis of a randomized leg. Biopsies were sampled from the same leg Pre, Post 4 , and Post 12 , approximately $2 \mathrm{~cm}$ proximal to the previous sample. One muscle sample was immediately snap-frozen in isopentane $\left(-80^{\circ} \mathrm{C}\right)$ and stored at $-80^{\circ} \mathrm{C}$ until further analyses of muscle protein content and activity, while the second biopsy was quickly dissected free of blood and visible connective tissue in ice-cold sterile saline solution $(0.9 \%$ $\mathrm{NaCl}$ ) and transferred to a $4 \%$ formalin solution for fixation for $24-72 \mathrm{~h}$, before further preparation for immunohistochemistry.

\section{0-min $T T$}

A standardized 16-min warm-up was performed prior to a 40-min TT. The participants performed the 40-min TT on their own bikes mounted on the same bike trainer (Tacx Neo Smart, Wassenaar, NL or Computrainer, Racermate, Seattle, United States). HR and power output were recorded throughout and $\left[\mathrm{Bla}^{-}\right]$and RPE were recorded every $5 \mathrm{~min}$. The participants were allowed to see the instantaneous power output but were blinded to the average power throughout the test. The participants were instructed to obtain the highest average power output during the test and encouraged to stay seated but standing cycling was allowed. After completion of the test, mean power output, mean and peak HR, RPE, and $\left[\mathrm{Bla}^{-}\right]$were registered.

\section{Hematological Measures}

Hematological measures were performed on a subset of the participants ( $n=8$ for TP, and $n=6$ for $\mathrm{BP}$ ) due to lack of equipment at one test center. The participants rested for $20 \mathrm{~min}$ in a semi-recumbent position and $\mathrm{Hb}$-mass was determined using a modified version of the carbon monoxide (CO) rebreathing technique, as described elsewhere (Siebenmann et al., 2012). Hb-mass was determined using OpCO (Detalo Performance, Detalo Health, Birkerød, Denmark). Briefly, the participant breathed $100 \% \mathrm{O}_{2}$ for $3 \mathrm{~min}$ before a blood sample was drawn from the antecubital vein $(125 \mathrm{ml})$ using pre-heparinized syringes (PICO50 80IU, Radiometer, DK) and immediately analyzed in triplicate for carboxy- $\mathrm{Hb}(\% \mathrm{HbCO})$ on a hemoximeter (ABL800, Radiometer, Copenhagen, Denmark). Subsequently, the participants rebreathed a bolus of chemically pure CO (Multigas SA, Domdidier, Switzerland) corresponding to $1.5 \mathrm{ml} \cdot \mathrm{kg}^{-1}$ for men and $1.0 \mathrm{ml} \cdot \mathrm{kg}^{-1}$ for women for $9 \mathrm{~min}$. A sensor registered and regulated the $\mathrm{O}_{2}$-level during the rebreathing. After rebreathing, another blood sample was drawn from the antecubital vein, analyzed for $\% \mathrm{HbCO}$ in triplicate. The change in \% $\mathrm{HbCO}$ between first and second measurement was used to calculate Hb-mass. Total red blood cell volume (RCV), total blood volume, and plasma volume was calculated 
from $\mathrm{Hb}$-mass and $\mathrm{Hb}$-concentration with the following calculations as described earlier (Siebenmann et al., 2015):

$$
\text { Hbmass }=644 \times n C O a b s \times 25 / \triangle H b C O
$$

where $\triangle \mathrm{HbCO}$ is the change in $\% \mathrm{HbCO}$ between the blood sample before and after administration of CO-dose.

$$
\begin{gathered}
R B C V(m l)=H b m a s s \times H c t /[H b] \\
B V(m l)=R B C V \times 100 / H c t \\
P V(m l)=B V \quad R B C V
\end{gathered}
$$

\section{Muscle Analyses Western Blotting}

Preparation and analyses of muscle tissue were conducted using the same protocol as previously described (26). Samples were homogenized for $\sim 120 \mathrm{~s}$ using a plastic pestle in $80 \mathrm{ml} \cdot \mathrm{mg}^{-1}$ fresh lysis buffer [ $2 \mathrm{mM}$ HEPES, $\mathrm{pH} 7.4 ; 1 \mathrm{mM}$ EDTA, $\mathrm{pH}$ 7.0; $5 \mathrm{mM}$ EGTA, pH 7.5; $10 \mathrm{mM} \mathrm{MgCl}_{2} ; 1 \%$ Triton-X-100; phosphatase, and protease inhibitors]. Subsequently to homogenization the samples were rotated end-over-end for $1 \mathrm{~h}$ and centrifuged for $10 \mathrm{~min}$ at $10,000 \mathrm{~g}$ to separate undissolved tissue from the supernatant. Afterward, the supernatant was carefully separated from the pellet and stored at $-80^{\circ} \mathrm{C}$ until further analysis. Protein concentration was determined using the Pierce Detergent Compatible Bradfor Assay Kit \#23246. Briefly, $5 \mathrm{ml}$ samples were diluted $1: 10$ in $\mathrm{ddH}_{2} \mathrm{O}$ and loaded in triplicates onto a 96-well microtiter plate, mixed with $250 \mathrm{ml}$ Pierce Detergent Compatible Bradford Assay Reagent, and measured spectrophotometrically at $595 \mathrm{~nm}$ using a Multiscan FC microplate reader (Thermo Fisher Scientific), using the SkanIt software 2.5.1 for Multiscan (Thermo Scientific). Pierce Serum Albumin standards with protein concentrations ranging from 0.025 to $2.0 \mathrm{mg} \cdot \mathrm{ml}^{-1}$ were used to create a standard curve. Protein concentrations were calculated from the standard curve after correction for the absorbance of the $\mathrm{ddH}_{2} \mathrm{O}$.

The lysates were normalized to a protein concentration of $2.0 \mathrm{mg} \cdot \mathrm{ml}^{-1}$ in ice-cold fresh buffer containing: $10 \%$ glycerol, $20 \mathrm{mM}$ Na-pyrophosphate, $150 \mathrm{NaCl}, 50 \mathrm{mM}$ HEPES ( $\mathrm{pH}$ 7.5), $1 \%$ NP-40, $20 \mathrm{mM} \beta$-glycerophosphate, $2 \mathrm{mM}$ Na3VO4, $10 \mathrm{mM}$ NaF, 2 mM PMSF, 1 mM EDTA (pH 8), 1 EGTA (pH 8), $10 \mu \mathrm{g} / \mathrm{ml}$ Aprotinin, $10 \mu \mathrm{g} / \mathrm{ml}$ Leupeptin, and $3 \mathrm{mM}$ Benzamidine. The samples were subsequently rotated end-over-end for $1 \mathrm{~h}$ at $4^{\circ} \mathrm{C}$ and centrifuged at $18,320 \mathrm{~g}$ for $20 \mathrm{~min}$ at $4^{\circ} \mathrm{C}$ to exclude non-dissolved structures. The lysates were prepared with a $4 \mathrm{x}$ Laemmli sample buffer (Bio-Rad Laboratories AB, Oslo, Norway) containing $10 \%$ 2-Mercaptoethanol and heated for $5 \mathrm{~min}$ at $95^{\circ} \mathrm{C}$. Proteins samples (15 mg of total protein) were separated at $300 \mathrm{~V}$ for 60 min using an Invitrogen gel (4-20\% Criterion ${ }^{\mathrm{TM}} \mathrm{TGX}^{\mathrm{TM}}$ Precast Midi Protein Gel, 26 well, $15 \mu \mathrm{l})$, followed by wet transfer to a PVDF membrane $(0.2 \mathrm{~mm}$ Immuno-Blot, Bio-Rad) at $400 \mathrm{~mA}$ for $60 \mathrm{~min}$. For each participant, all samples were loaded on the same gel in technical duplicates. Membranes were then stained using a reversible total protein stain (Pierce Reversible Protein Stain, Thermo Fischer Scientific) to ensure appropriate protein transfer and to control for loading. Membranes were then blocked using 3\% Bovine Serum Albumin in Tris-buffered saline including $0.1 \%$ Tween-20 (TBST) for $60 \mathrm{~min}$ at room temperature, before overnight incubation in primary antibody on a rocking table at $4^{\circ} \mathrm{C}$. Membranes were then washed $2 \times 5 \mathrm{~min}$ in TBST, followed by incubation in a TBST-solution containing 5\% skimmed milk and horseradishperoxidase-conjugated secondary antibody for $60 \mathrm{~min}$ at room temperature. The membranes were then washed $4 \times 5 \mathrm{~min}$ in TBS-T, and bands were visualized using chemiluminescent detection (Immobilon Forte, Western HRP Substrate, Millipore) and recorded with a digital camera (ChemiDoc XRS+, BioRad Laboratories). Band intensities were quantified using Image Lab 6.0.1 (Bio-Rad, Laboratories), adjusted for background intensity. Samples were normalized to a human pool (HP) containing equal amounts of all Pre-samples, which was loaded onto each gel in duplicates. Primary antibodies were purchased from Abcam; Anti-Citrate synthase (CS), 1:2,000 (ab96600), anti-cytochrome $\mathrm{c}$ oxidase subunit IV (COXIV), 1:4,000 (ab156056), anti- $\beta$-hydroxyacyl (HAD), 1:8,000 (ab154088), Santa Cruz Biotechnology; phosphofructokinase 1 (PFK-1), 1:500 (sc166722), and Thermo Fischer Scientific; Sodiumpotassium pump $\beta 1$ subunit $\left(\mathrm{Na}^{+}-\mathrm{K}^{+} \beta 1\right), 1: 1,000$ (MA3-930), and DSHB; Sodium-potassium pump $\alpha$ subunits $\left(\mathrm{Na}^{+}-\mathrm{K}^{+} \alpha\right)$, 1:60 (alfa5-S).

\section{Enzyme Activity}

Citrate synthase and phosphofructokinase (PFK) activity were assayed in muscle lysates using commercially available kits (CS: CS0720, PFK: MAK093, St. Louis, MO, Sigma-Aldrich) according to the manufacturer's instructions as described previously (42). All activities were normalized to protein concentration as described above and expressed in international $\mathrm{mU} \cdot \mathrm{mg}^{-1}$ protein.

\section{Histochemical Analyses of Muscle Fiber Size and Capillarization}

Formalin-fixed muscle biopsies were processed rapidly using a Shandon Excelsior ES (Thermo Fisher Scientific, Waltham, MA, United States). After that, biopsies were paraffin-embedded and sectioned into $4 \mu \mathrm{m}$ transverse sections. Antigen retrieval was performed at $97^{\circ} \mathrm{C}$ for $20 \mathrm{~min}$ in a target retrieval solution (cat. no. DM828, Agilent Dako, Santa Clara, CA, United States) using a PT link (PT 200, Agilent Dako, Santa Clara, CA, United States). Staining was performed using a DAKO Autostainer Link 48 (Agilent Dako, Santa Clara, CA, United States). To determine muscle fiber cross-sectional area, fiber type, numbers of myonuclei per muscle fiber type, capillary density (CD), capillaries around fibers (CAF) per fiber type, and capillaries to fiber ratio $(C F)$, cross-sections were triple stained using primary antibodies against muscle fiber membrane (dystrophin, diluted 1:100, cat. no. PA1-37587; Thermo Fisher Scientific, Waltham, MA, United States), myosin heavy chain I (diluted 1:2,000, cat. no. M8421, Sigma-Aldrich, Saint-Louis, MO, United States), and CD34 (diluted 1:50, cat. no. M7165, DAKO Agilent). Visualization was achieved using the secondary antibodies Alexa Fluor 594 (IgG $\mathrm{H}+\mathrm{L}$, diluted 1:400, cat. no. A11037) and 488 (IgG1 $\gamma 1$, diluted 1:400, cat. no. A21121), 
respectively (Thermo Fisher Scientific, Waltham, MA, United States). CD34 was visualized using EnVision ${ }^{\mathrm{TM}}$ high pH (Link) kit (cat. no K8000, DAKO Agilent). Muscle sections were then covered with a coverslip and glued with EverBrite ${ }^{\mathrm{TM}}$ Hardset Mounting Medium containing DAPI (cat. no. 23004, Biotium Inc., Fremont, CA, United States) to visualize cell nuclei. Images of stained cross-sections were captured using a high-resolution camera (Axiocam, Zeiss, Oberkochen, Germany) mounted on a light microscope (Axioskop-2, Zeiss, Oberkochen, Germany), with a fluorescent light source (X-Cite 120, EXFO Photonic Solutions Inc., Mississauga, Canada). Multiple images were taken using $10 \times$ objectives to capture the entirety of each cross-section. Analyses were performed using an automated procedure CellProfiler 4.2.1 (Carpenter et al., 2006) ensuring an unbiased quantification. On average, $234 \pm 155$ fibers were analyzed per muscle sample.

\section{Statistics}

All variables were tested for normal distribution using the Shapiro-Wilk test and were log-transformed to obtain normality if not normal. To compare relative changes in physiological, performance, muscular (\% changes from Pre), and hematological measures from Pre to Post 4 and Pre to Post12 between groups, a mixed linear model was applied with group defined as fixed effects and corrected using Pre-values as a covariate using the software SPSS v.25. For all immunohistochemical measures (CSA, fiber type proportion, capillary, and nuclei measures), the models were weighted for the number of fibers counted in each sample to account for the reduced reliability of fewer fibers. To compare main effects of time and group a mixed linear model was applied with fixed effects defined by group and time and random effects were defined by subject. Performance and physiological measures are presented as mean $\pm S D$, while estimated marginal means (EMM) of \% changes in muscular measures are mean $\pm 95 \%$ CI. Post hoc analyses were performed with Sidak adjustments using an alpha-level of 0.05 .

\section{RESULTS}

\section{Performance Measures}

There were no differences in the effect of training between TP and BP in 5-min $(p=0.940)$ and $40-\mathrm{min} \mathrm{TT}(p=0.612)$ power output relative to body mass, but when pooling the groups, training increased 5 and 40 -min TT power output by $8.9 \pm 8.9 \%$ $(p<0.001)$ and $8.4 \pm 9.0 \%(p<0.001)$, respectively (Figures 2A-C). Likewise, for $\mathrm{W}_{\max }$, there was no difference in the effect of training between TP and BP $(p=0.511)$, but pooled data showed a $2.4 \pm 4.5 \%(p=0.016)$, and a $6.3 \pm 6.6 \%(p=0.001)$ improvement of $\mathrm{W}_{\max }$, respectively, from Pre to Post 4 and Pre to Post12.

\section{Performance-Related Measures}

There was no difference between $\mathrm{TP}$ and $\mathrm{BP}$ in the effect of training on $\mathrm{VO}_{\text {2peak }}$ (interaction effect: $p=0.94$ ), and neither group changed $\mathrm{VO}_{2 \text { peak }}$ from Pre to Post 4 or Post12 (all $p>0.11$; Figure 2D). There was no difference between $\mathrm{TP}$ and $\mathrm{BP}$ in the effect of training on $\mathrm{W}_{4 \mathrm{mmol}}$ (interaction effect: $p=0.31$, Figure 2E) or on the fractional utilization of $\mathrm{VO}_{2}$ at $\mathrm{W}_{4 \mathrm{mmol}}$ (interaction effect: $p=0.100$; Figure 2F). However, pooled data showed an effect of time where $\mathrm{W}_{4 \mathrm{mmol} \cdot \mathrm{kg}}{ }^{-1}$ increased by $10.2 \pm 12.4 \%(p=0.001)$ from Pre to Post12 and the fractional utilization of $\mathrm{VO}_{2}$ at $\mathrm{W}_{4 \mathrm{mmol}}$ increased in by $5.0 \pm 8.5 \%$-points $(p=0.026)$.

Likewise, there was no difference between $\mathrm{TP}$ and $\mathrm{BP}$ in the effect of training on maintaining GE from the fresh to the semi-fatigued state (interaction effect: $p=0.34$ ). Pooled data showed that training reduced the deterioration of GE by $0.5 \pm 1.1 \%$-points $(p=0.026)$ from Pre to Post $12 . \% \mathrm{VO}_{2 \text { peak }}$ during the 5-min TT, $\% \mathrm{HR}_{\text {peak }}$ during the 40 -min TT, and 6-s all-out peak power was not affected by training in BP or TP (Table 2).

\section{Skeletal Muscle Measures}

There was no difference between TP and BP in any protein content alteration from Pre to Post 4 or Pre to Post12 (Figure 3). Pooled data showed an effect of time for $\operatorname{HAD}(p=0.037)$, $\operatorname{COXIV}(p=0.005), \mathrm{Na}^{+}-\mathrm{K}^{+} \alpha(p=0.036)$, and $\mathrm{Na}^{+}-\mathrm{K}^{+} \beta 1 \quad(p=0.015)$. Post hoc analyses revealed a $55 \pm 58 \%(p=0.048)$ increase in HAD protein content in TP from Pre to Post12, while protein content of COXIV increased in both TP and BP from Pre to Post 12 by $88 \pm 54 \% \quad(p=0.037)$, and $79 \pm 60 \% \quad(p=0.041)$, respectively. Enzyme activity of CS and PFK did not change differently between groups. However, for CS there was an effect of time ( $p=0.043)$ when pooling the groups, but post hoc tests neither showed alterations in TP $(12 \pm 35 \%, p=0.367)$ nor BP $(22 \pm 33 \%, p=0.051)$ from Pre to Post 12 . No other changes were observed within either group from Pre to Post 4 or Post 12.

\section{Muscle Morphological and Capillary Measures}

Traditional periodization led to different alterations in $\mathrm{C} / \mathrm{F}$-ratio (interaction $p=0.045$ ) and CAF type I (interaction $p=0.049$ ) than BP. C/F-ratio increased $19 \pm 18 \%(p=0.038)$ more in TP from Pre to Post 4 compared to BP, and CAF type I increased $20 \pm 12 \%$ $(p=0.002)$ more in TP from Pre to Post12 than BP (Table 3). The effect of training was otherwise similar between groups.

Generally, for pooled data, there was an effect of time for $\mathrm{CD}(p=0.011)$, C/F-ratio $(p<0.001)$, CSA type II fibers $(p=0.032)$, CAF type II fibers $(p=0.024)$, and nuclei per fiber type II $(p=0.042)$. Specifically in TP, C/F-ratio increased by $27 \pm 12 \%$ $(p=0.021)$ and by $36 \pm 15 \%(p<0.001)$ from Pre to Post 4 and Post12, respectively, while CAF type I increased by $17 \pm 8 \%$ $(p=0.025)$ from Pre to Post12. In BP, CSA of type II fibers decreased by $19 \pm 11 \%(p=0.032)$ from Pre to Post 4 , while CD increased by $28 \pm 24 \%$ ( $p=0.048)$ in BP from Pre to Post 12 . Nuclei per fiber type I were lower in BP compared to TP at Post4 (post hoc $p=0.010$ ). Post hoc did not show any other changes within either group from Pre to Post 4 or Post12.

\section{Hematological Measures}

There was a different effect of training between TP and BP on RBCV (interaction effect $p=0.017$ ) and HB-mass (interaction effect $p=0.014$; Figure 4) in favor of BP. Specifically, BP 


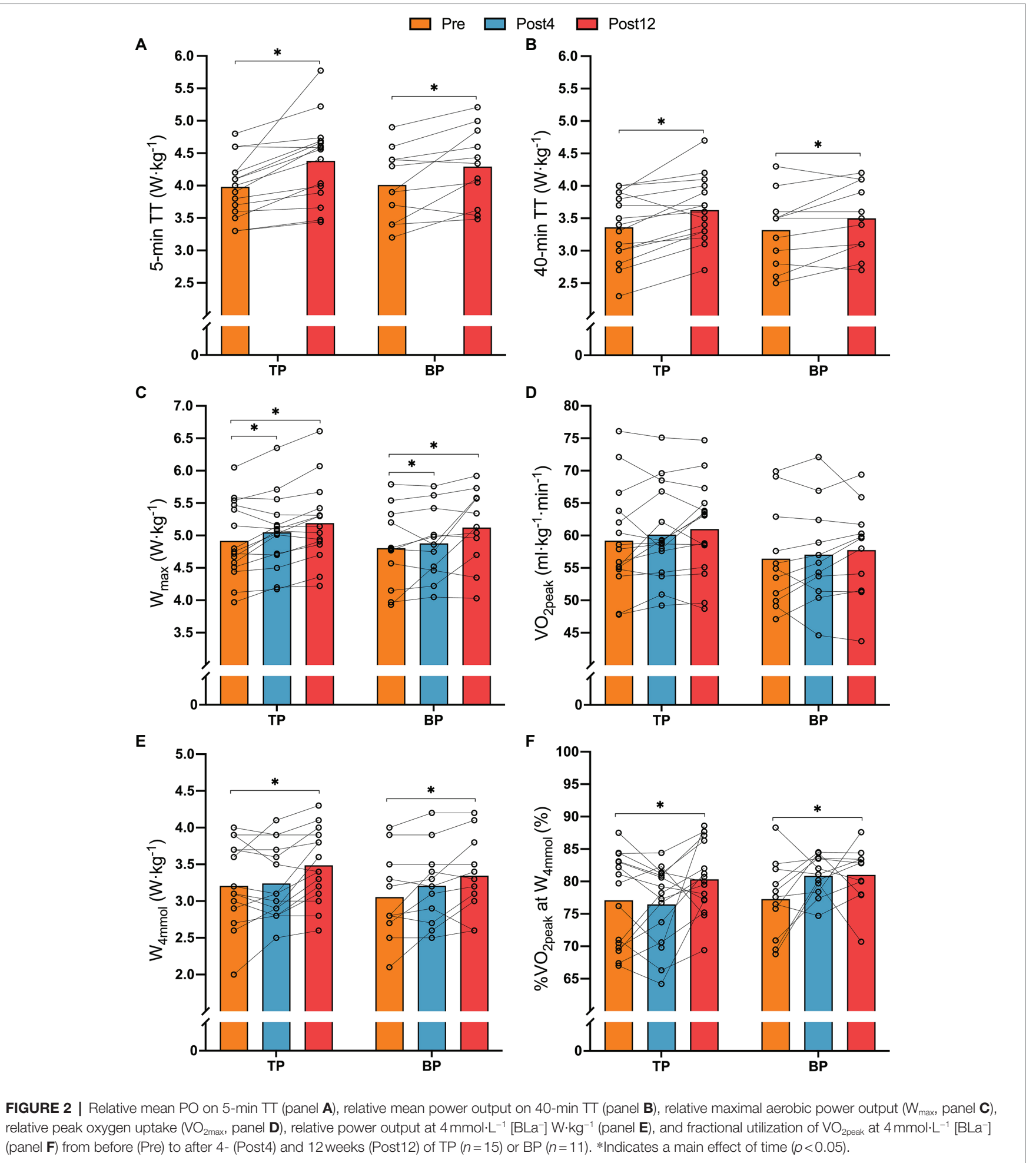

increased RBCV $10 \pm 16 \%(p=0.029)$ more than TP from Pre to Post 12 (TP: $-3 \pm 7 \%$ vs. BP: $7 \pm 8 \%$ ), while post hoc analyses showed no differences in HB-mass changes between TP and BP (TP: $-1 \pm 7 \%$ vs. BP: $5 \pm 4 \%, p=0.103$ ) from Pre to Post12. No other differences were observed between or within TP and BP from Pre to Post 4 or Post12.

\section{DISCUSSION}

This study compared 12 weeks of training load-matched BP, using concentrated HIT-, MIT-, and LIT-weeks, with a TP using a mix of HIT-, MIT-, and LIT-sessions and a cyclic progressive increase in training load in trained cyclists. 
TABLE 2 | Body mass, performance-related measures, and 6-s all-out sprint peak power before (Pre) to after 4 (Post4) and 12 weeks (Post12) of traditional periodization (TP, $n=15$ ) and blocked periodization (BP, $n=11$ ).

\begin{tabular}{|c|c|c|c|c|}
\hline & \multicolumn{2}{|c|}{ TP } & \multicolumn{2}{|c|}{ BP } \\
\hline & Pre & Post12 & Pre & Post12 \\
\hline $\begin{array}{l}\text { Body mass } \\
(\mathrm{kg})\end{array}$ & $82.3 \pm 11.2$ & $81.6 \pm 9.8$ & $76.5 \pm 9.2$ & $76.4 \pm 8.8$ \\
\hline $\begin{array}{l}\% \mathrm{VO}_{2 \text { peak }} 5-\mathrm{min} \\
\mathrm{TT}(\%)\end{array}$ & $88.5 \pm 4.4$ & $90.0 \pm 4.3$ & $89.4 \pm 5.8$ & $90.2 \pm 4.1$ \\
\hline $\begin{array}{l}\% \mathrm{HR}_{\text {peak }} 40- \\
\min T \mathrm{~T}(\%)\end{array}$ & $91.6 \pm 4.2$ & $91.3 \pm 3.7$ & $93.1 \pm 2.4$ & $92.3 \pm 3.8$ \\
\hline GE fresh (\%) & $19.4 \pm 1.9$ & $19.2 \pm 1.6$ & $18.5 \pm 2.2$ & $18.7 \pm 2.3$ \\
\hline $\begin{array}{l}\text { GE semi- } \\
\text { fatigued (\%) }\end{array}$ & $18.5 \pm 2.1$ & $18.8 \pm 1.6 *$ & $18.0 \pm 1.4$ & $18.6 \pm 2.0 *$ \\
\hline $\begin{array}{l}\text { GE fresh vs. } \\
\text { semi-fatigued }\end{array}$ & $-0.9 \pm 0.9$ & $-0.3 \pm 0.8 *$ & $-0.5 \pm 1.1$ & $-0.1 \pm 1.0 *$ \\
\hline $\begin{array}{l}\text { 6-s peak } \\
\text { power }\left(\mathrm{W} \cdot \mathrm{kg}^{-1}\right)\end{array}$ & $17.0 \pm 3.3$ & $17.1 \pm 3.1$ & $15.0 \pm 3.7$ & $15.3 \pm 3.6$ \\
\hline
\end{tabular}

[BLa-], blood lactate concentration measured $1 \mathrm{~min}$ after conclusion of 5 and 40-min time-trial (TT); RPE, rate of perceived exertion immediately after 5 and 40-min TT; GE, gross efficiency measured in steady-state periods in the fresh and the semi-fatigued state during the $\sim 2-h$ long test protocol; and $\Delta G E$, change in gross efficiency from the fresh to the semi-fatigued state (\%-points). *Indicates a significant change from Pre to Post12 ( $p<0.05)$.

$\mathrm{TP}$ and BP did not lead to different improvements in TT performances, performance-related measures, muscle protein content, or enzyme activity after 4 and 12 weeks of supervised endurance training. However, RBCV, was increased by $10 \%$ more in $\mathrm{BP}$ compared to $\mathrm{TP}$ after 12 weeks, while C/F-ratio increased $19 \%$ more in TP from Pre to Post 4 but not Post12, and CAF type I increased $20 \%$ more from Pre to Post 12 compared to BP. Otherwise, no differences were observed in responses to training between TP and BP. Overall, substantial improvements in performance (5 and 40-min TT power output) and performance-related measures $\left(\mathrm{W}_{\max }\right.$ and $\left.\mathrm{W}_{4 \mathrm{mmol}}\right)$, muscular protein content of HAD and COXIV, and GE in the fatigued state were evident in both $\mathrm{BP}$ and TP.

In the current study, no clear differences in performance or performance-related measures between the two periodization models were observed. These findings contrast the findings of a recent meta-analysis by Molmen et al. (2019), indicating a small benefit of using BP. However, the findings of the different studies included in that metaanalysis ranged from no performance-benefits of BP over TP (Breil et al., 2010; Garcia-Pallares et al., 2010; McGawley et al., 2017), to moderate, positive effects on performance and performance-related measures (e.g., $\mathrm{VO}_{2 \text { peak }}, \mathrm{W}_{\max }$, and $\mathrm{W}_{4 \mathrm{mmol}}$ ) in both trained, and highly trained athletes (Breil et al., 2010; Ronnestad et al., 2012, 2014, 2016; Clark et al., 2014; Costa et al., 2017). Differences across studies might relate to differences in training design, including duration, load administration, performance level, and distribution of training at different intensities. The present study is characterized by the combination of a long duration (12 weeks), well-controlled, supervised sessions with high adherence (92\%), and a "best practice" TP with a cyclic, progressive increase in training load. Previous studies have not used such a gradual increase in numbers of MIT and HIT intervals from each week when applying a TP approach. This cyclic increase in training load could, hence, be speculated to prevent staleness in training stimuli as previously suggested (Goutianos, 2016), leading to similar improvements in performance and performance-related outcomes as BP after both shorter ( 4 weeks) and longer (12 weeks) training periods. Additionally, MIT exercise has rarely been included in studies comparing $\mathrm{BP}$ and $\mathrm{TP}$ and is thus a distinctive quality of our study. We found substantial improvements of several endurance performance measures such as $\mathrm{W}_{\max }(6 \%), \mathrm{W}_{4 \mathrm{mmol}}$ $(\sim 10 \%)$, and fractional utilization of $\mathrm{VO}_{2}$ at $\mathrm{W}_{4 \mathrm{mmol}}(\sim 5 \%)$ in both TP and BP when including MIT, suggesting an applicability of MIT in both blocked-, and traditionally periodized programs. In support of this, Garcia-Pallares et al. (2010) included MIT and HIT intensity ranges in their comparison of BP and TP and found $~ 10 \%$ improvements in $\mathrm{VO}_{2}$ at the second ventilatory threshold. However, the use of both different durations of the MIT periods and intensity distribution during the BP and TP (Garcia-Pallares et al., 2010), makes comparisons with the present study difficult.

Additionally, the performance level and training history of our participants may have influenced our findings. The participants were generally "trained" but with rather diverging performance levels (level 2-5), making the potential for improvement highly individual. Accordingly, both groups achieved substantial improvements in performance outcomes and muscular adaptations. BP and TP groups were pairmatched based on the mean power output of a 40-min TT and total training load during the intervention. However, the individual, relative change in training load compared to habitual training load differed greatly and could be a reason for the substantial and similar improvements seen. The summary by Molmen et al. (2019) indicates that BP only has a small benefit over TP in athletes with the weighted mean $\mathrm{VO}_{2 \text { peak }}$ of $60 \mathrm{ml} \cdot \mathrm{kg}^{-1} \cdot \mathrm{min}^{-1}$ (Molmen et al., 2019). It could be argued that the large and diverging improvements found in our participants would mask potential differences between BP and TP. However, the performance level of participants was similar in Molmen et al. (2019); hence, the lack of difference between BP and TP cannot fully be explained by the performance level of our participants.

Still, a previous study in a homogenous group of welltrained cyclists revealed moderate beneficial effects of $\mathrm{BP}$ over TP (Ronnestad et al., 2014), which could underline the need for a more concentrated training focus for athletes closer to their genetic maximum (Psilander et al., 2010) than the present participants. Another potential factor might be that our blocks included only four sessions of MIT or HIT each week, which is less than previous blocks used in studies by Ronnestad et al. (2012, 2014, 2016), where they included five sessions of HIT each week and found superior effects of BP over TP. However, the lack of a difference between $\mathrm{BP}$ and TP could be the result of a more successful 

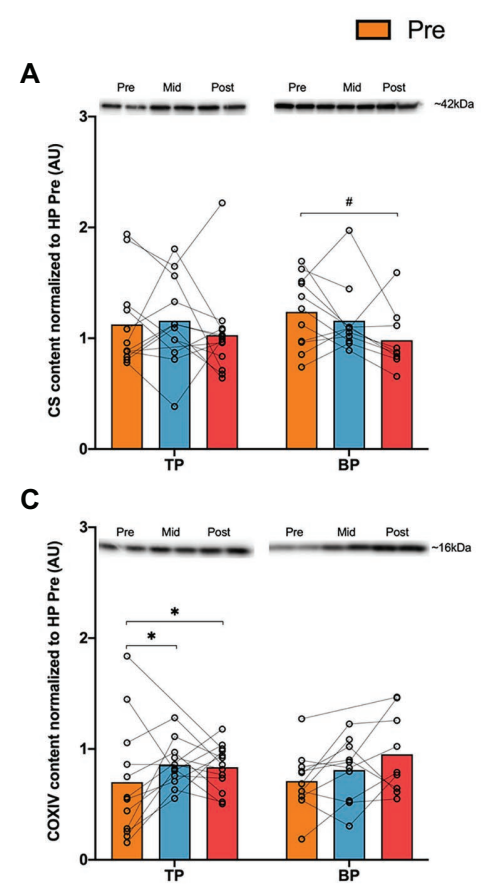

\section{Post4 $\square$ Post12}

B

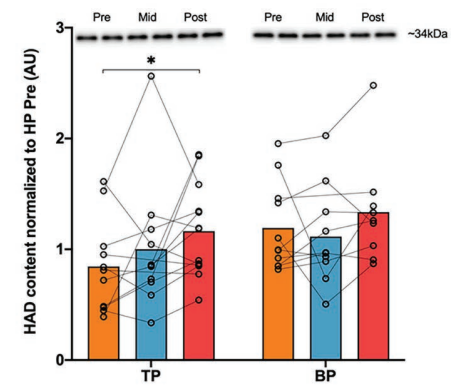

D

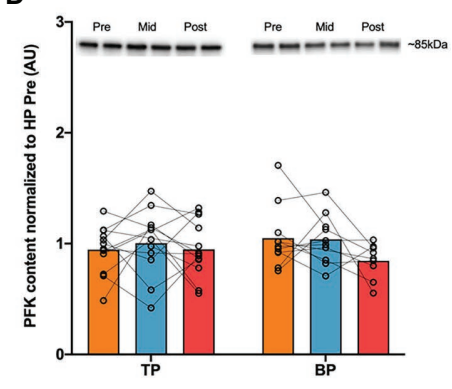

E

F
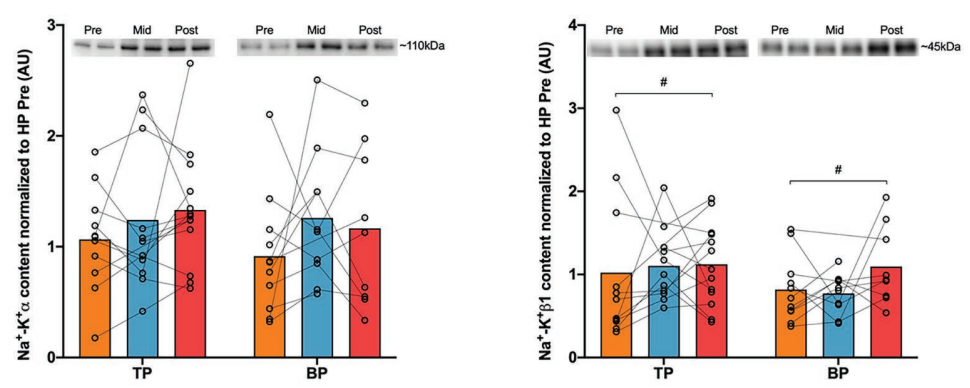

G

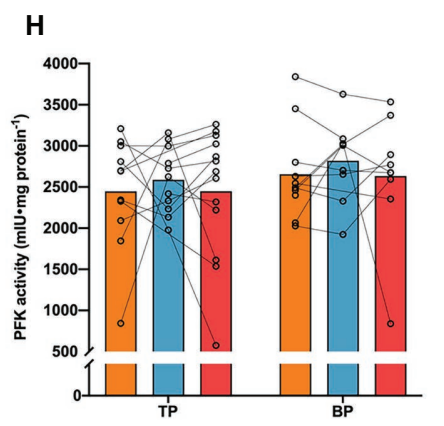

FIGURE 3 | Muscle protein quantities (panels A-D) and activities (panels E,F) in $\mathrm{m}$. vastus lateralis before and after 4 (Post4) and 12 weeks (Post12) of TP $(n=13)$ and BP $(n=10)$. Panel (A), Citrate synthase (CS); panel (B), $\beta$-hydroxyacyl (HAD); panel (C), Cytochrome c oxidase subunit 4 (COXIV); panel (D), phosphofructokinase (PFK); panel (E), Sodium-potassium pump $\alpha\left(\mathrm{Na}^{+}-\mathrm{K}^{+} \alpha\right)$; panel (F), Sodium-potassium pump $\beta 1$ ( $\left.\mathrm{Na}^{+}-\mathrm{K}^{+} \beta 1\right)$; panel (G), enzyme activity of citrate synthase; and panel (H), enzyme activity of phosphofructokinase. Individual band-intensities were expressed relative to total protein stain and normalized to a human pool (HP) containing equal amounts of all Pre-samples. Mean and individual values. *Indicates post hoc effect of time $(p<0.05)$.

administration of a "best practice" cyclic training load increase in TP than previous studies, leading to similar performance adaptations as BP.

The improvements of GE and performance in a fatigued state provide some additional insights. GE in the semi-fatigued state, but not in the fresh state, was improved in both BP and TP by the 12-week intervention; hence, a smaller decrease in GE from the fresh to the semi-fatigued state was observed in both groups. Previous studies in trained and competitive cyclists have reported, moderate effects in 
TABLE 3 | Skeletal muscle morphological measures, capillarization and cell nuclei from before (Pre) to after 4 weeks (Post4), and 12 weeks (Post12) of TP ( $n=13)$ and $\operatorname{BP}(n=11)$.
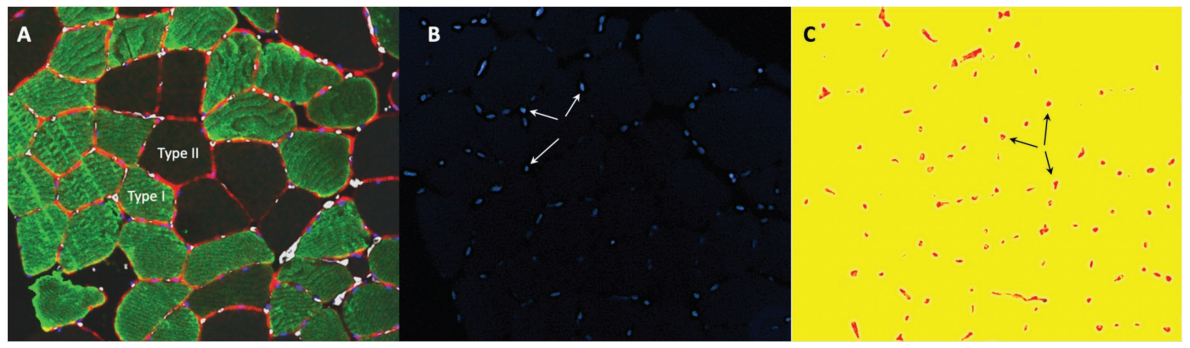

TP

\begin{tabular}{|c|c|c|c|c|c|c|}
\hline & & \\
\hline & Pre & Post4 & Post12 & Pre & Post4 & Post12 \\
\hline Type I fibers (\%) & $66 \pm 7$ & $68 \pm 6$ & $69 \pm 5$ & $67 \pm 6$ & $69 \pm 7$ & $62 \pm 6$ \\
\hline $\mathrm{CD}\left(\mathrm{cap} / \mathrm{mm}^{2}\right)$ & $418 \pm 79$ & $463 \pm 74$ & $494 \pm 63$ & $426 \pm 72$ & $505 \pm 83$ & $518 \pm 71 *$ \\
\hline C/F-ratio (cap/fiber) & $1.7 \pm 0.3$ & $2.2 \pm 0.3 * \S$ & $2.4 \pm 0.3^{*}$ & $1.8 \pm 0.3$ & $1.8 \pm 0.4$ & $2.1 \pm 0.3$ \\
\hline CSA type I fibers $\left(\mu \mathrm{m}^{2}\right)$ & $4,379 \pm 597$ & $4,533 \pm 569$ & $4,803 \pm 531$ & $4,226 \pm 581$ & $3,787 \pm 637$ & $4,231 \pm 584$ \\
\hline CSA type II fibers $\left(\mu \mathrm{m}^{2}\right)$ & $4,537 \pm 802$ & $4,816 \pm 786$ & $5,041 \pm 744$ & $4,802 \pm 797$ & $3,897 \pm 865 *$ & $4,892 \pm 791$ \\
\hline CAF type I & $5.5 \pm 0.9$ & $5.5 \pm 0.9$ & $6.7 \pm 0.8 * \S$ & $5.1 \pm 0.9$ & $4.9 \pm 1.0$ & $4.9 \pm 0.9$ \\
\hline CAF type $\|$ & $5.1 \pm 1.0$ & $4.8 \pm 0.9$ & $5.8 \pm 0.8$ & $4.8 \pm 0.9$ & $3.9 \pm 1.0$ & $4.6 \pm 0.9$ \\
\hline CAFA type I (CAF/CSA) & $1.3 \pm 0.3$ & $1.2 \pm 0.2$ & $1.4 \pm 0.2$ & $1.3 \pm 0.2$ & $1.4 \pm 0.3$ & $1.3 \pm 0.2$ \\
\hline CAFA type II (CAF/CSA) & $1.2 \pm 0.2$ & $1.0 \pm 0.2$ & $1.2 \pm 0.2$ & $1.0 \pm 0.2$ & $1.2 \pm 0.3$ & $1.1 \pm 0.2$ \\
\hline Nuclei per fiber type I & $2.3 \pm 0.4$ & $2.7 \pm 0.3^{\#}$ & $2.7 \pm 0.3$ & $2.2 \pm 0.3$ & $2.0 \pm 0.4$ & $2.4 \pm 0.3$ \\
\hline Nuclei per fiber type II & $2.3 \pm 0.4$ & $2.6 \pm 0.4$ & $2.8 \pm 0.4$ & $2.6 \pm 0.4$ & $2.1 \pm 0.4$ & $2.7 \pm 0.4$ \\
\hline
\end{tabular}

Representative images of A: Fiber types I (green) and II (black), B: Cell nuclei (b/ue), and C: Capillaries (red). CD, capillary density; C/F-ratio, capillary-to-fiber ratio; CSA, crosssectional area; CAF, capillaries around fibers; and CAFA, capillaries around fibers per cross-sectional area.

*Indicates post hoc difference from Pre $(p<0.05)$.

"Indicates main effect of group.

sIndicates an interaction (time $\times$ group, $p<0.05$ ).

exercise economy for $\mathrm{BP}$ over $\mathrm{TP}$, although non-significant (Clark et al., 2014; Ronnestad et al., 2014). Contrasting this, McGawley et al. (2017) showed improvement in skiing economy for TP only, although not different from BP. The 5 -min time trial, which was started in a semi-fatigued state at the end of test day 1 also improved in both BP and TB. The two outcomes of improved GE and 5-min TT may have symbiotic effects because an improved GE in the fatigued state, given our current protocol, would save energy for utilization in the 5-min TT. Hence, our data support that consistent endurance training improves GE and performance in the fatiguing state in already trained athletes, which arguably is of importance for race-specific endurance performance. However, based on our findings and the cited literature, this improvement does not seem to be differently affected by the periodization model.

Interestingly, RBCV was increased in BP compared to TP, with $\mathrm{Hb}$-mass showing similar numerical advantage. Although not statistically different, the numerical advantage of a $5 \%$ increase in BP (vs. -1 in TP) could be physiologically relevant. Ronnestad et al. (2012) found similar alterations in Hb-mass, $\sim 5 \%$, as in the present study after 12 weeks of BP, while no changes were reported for TP. However, the lack of statistical power might have influenced the present and previous conclusions as hematological measures were only performed on a subset of the participants $(n=14)$ in the present study.
Several skeletal muscle measures were altered with TP and $\mathrm{BP}$, supporting the sound improvements in TT-performances herein. Muscle protein content of COXIV increased by 88 and $79 \%$ in TP and BP from Pre to Post12, while the content of HAD only increased in TP by $55 \%$. Previously, only McGawley et al. (2017) have reported muscular adaptations to TP and $\mathrm{BP}$ and found a $\sim 7 \%$ decrease in HAD-activity in BP, while CS and PFK activities, in line with our findings, were unaltered (McGawley et al., 2017). McGawley et al. (2017) did not find changes in capillary measures such as $\mathrm{CD}$, which could relate to the short duration of training ( 3 weeks) and high performance level of the participants. Capillary adaptations are reported after 4 weeks of endurance training in previously sedentary subjects (Hellsten and Nyberg, 2015). Similarly, after 4 weeks we found a $27 \%$ increase in C/F-ratio in TP, and a $36 \%$ increase after 12 weeks. Also, CAF type I was increased by $17 \%$ in $\mathrm{TP}$, whereas in BP, CD increased by $28 \%$ from Pre to Post12, underlining the sound peripheral adaptations of both periodization models.

Interestingly, C/F-ratio increased $19 \%$ more in TP from Pre to Post4, but this difference was not seen after 12 weeks. Also, CAF type I increased 20\% more from Pre to Post 12 compared to BP. The present diverging findings in capillarization might, however, be limited by the borderline low number of fibers included in the analysis (151 \pm 105 type I fibers, and $79 \pm 60$ type II fibers), since an average of at least 50 fibers of each 

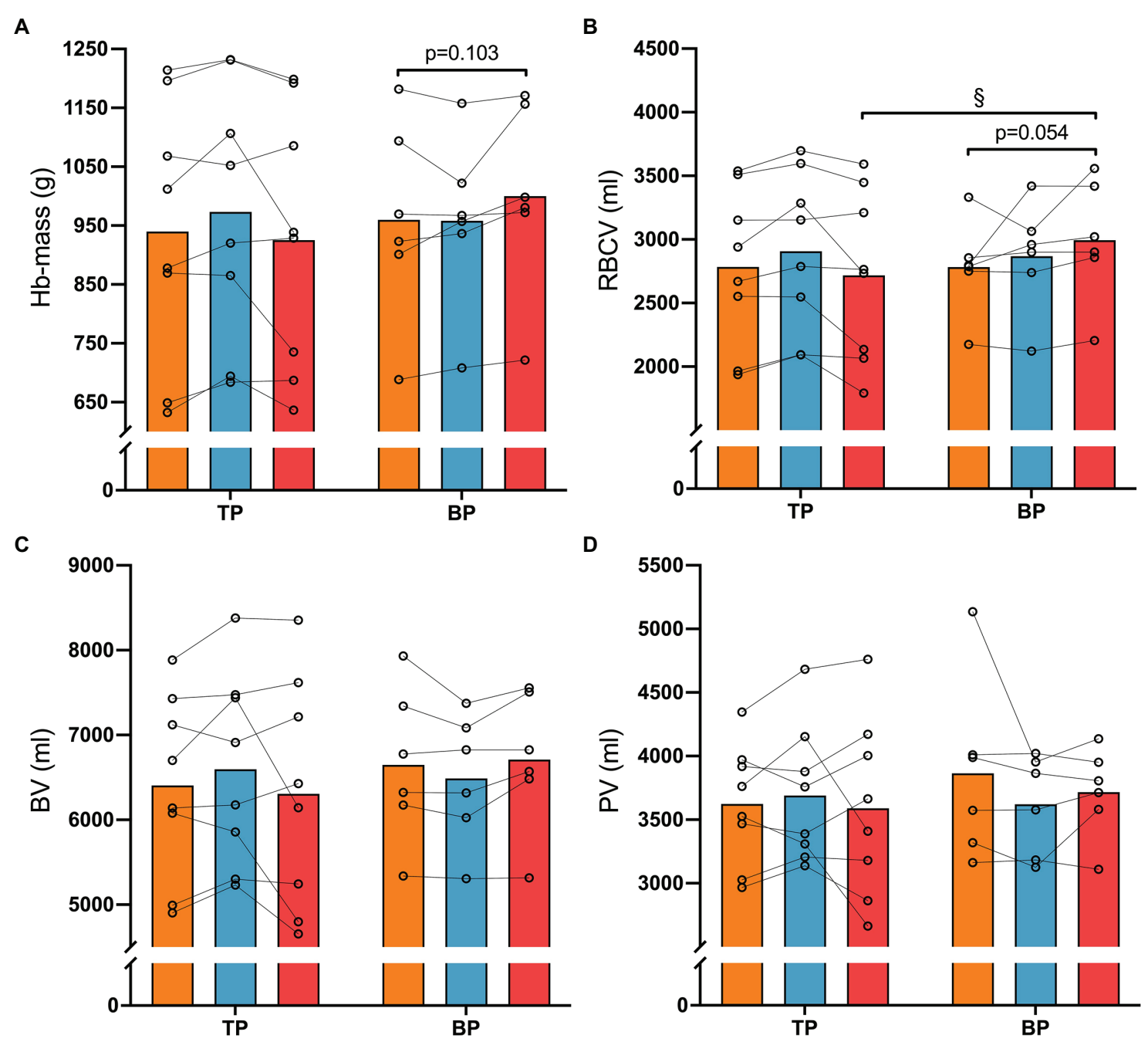

FIGURE 4 | Haematological measures before (Pre), after 4 weeks (Post4), and after 12 weeks (Post12) of traditional periodization (TP, $n=8$ ) and blocked periodization (BP, $n=6$ ). Panel (A), Haemoglobin mass (Hb-mass); Panel (B), Red blood cell volume (RBCV); Panel (C), Blood volume (BV); Panel (D), Plasma volume (PV). $\S$ indicates an interaction (time $\times$ group, $p<0.05$ ).

type ought to be included to acquire reliable measures (McCall et al., 1998). However, our findings support substantial improvements in muscle capillarization with both TP and BP. Although different alterations are observed between periodization models, these did not lead to different improvements of TT-performances in TP and BP.

\section{PRACTICAL APPLICATION}

Our data does not support the superiority of one periodization model over the other when LIT, MIT, and HIT are blocked vs. when a "best practice" cyclic progressive increase in training load is applied in TP over a 12-week training period in trained cyclists. These findings are in line with a case study of the world's best XC-skier who succeeded with both TP and BP during her career (Solli et al., 2019), supporting the applicability of both periodization models. We did not find differences in performance after 4 weeks of TP and $\mathrm{BP}$; however, equivocal findings exist where BP has shown larger improvements than TP in performance measurements (Breil et al., 2010; Ronnestad et al., 2012, 2014, 2016; Clark et al., 2014; Molmen et al., 2019). Using BP as an individualized approach for coaches could be suggested when seeking to alternate training stimuli in athletes. The application of a short BP training period (e.g., a 5-7 day micro cycle) can provide a substantial overload stimulus in a targeted ability. This is not an argument for one periodization model over the other, but a proposal for BP as a tool, which can be applied to the training of athletes in specific situations.

\section{CONCLUSION}

In conclusion, our data does not support the hypothesis that $\mathrm{BP}$ is superior to a "best practice"-TP using a cyclic, progressively 
increasing training load in improving the endurance performance of trained cyclists. Although hematological and muscle capillary adaptations differed, 12 weeks of training led to similar improvements in performance (5 and 40 -min TT power output) and performance-related measures $\left(\mathrm{W}_{\max }\right.$ and $\left.\mathrm{W}_{4 \mathrm{mmol}}\right)$, muscular protein content of HAD and COXIV, and GE in the fatigued state in both BP and TP.

\section{DATA AVAILABILITY STATEMENT}

The raw data supporting the conclusions of this article will be made available by the authors, without undue reservation.

\section{ETHICS STATEMENT}

The studies involving human participants were reviewed and approved by Local ethical committee at Lillehammer

\section{REFERENCES}

Almquist, N. W., Løvlien, I., Byrkjedal, P. T., Spencer, M., Kristoffersen, M., Skovereng, K., et al. (2020). Effects of including sprints in one weekly low-intensity training session during the transition period of elite cyclists. Front. Physiol. 11:1000. doi: 10.3389/fphys.2020.01000

Breil, F. A., Weber, S. N., Koller, S., Hoppeler, H., and Vogt, M. (2010). Block training periodization in alpine skiing: effects of 11-day $\mathrm{HIT}$ on $\mathrm{VO}_{2 \max }$ and performance. Eur. J. Appl. Physiol. 109, 1077-1086. doi: 10.1007/ s00421-010-1455-1

Carpenter, A. E., Jones, T. R., Lamprecht, M. R., Clarke, C., Kang, I. H., Friman, O., et al. (2006). CellProfiler: image analysis software for identifying and quantifying cell phenotypes. Genome Biol. 7:R100. doi: 10.1186/ gb-2006-7-10-r100

Clark, B., Costa, V. P., O'brien, B. J., Guglielmo, L. G., and Paton, C. D. (2014). Effects of a seven day overload-period of high-intensity training on performance and physiology of competitive cyclists. PLoS One 9:e115308. doi: 10.1371/ journal.pone.0115308

Costa, V. P., Guglielmo, L. G., and Paton, C. D. (2017). The effects of block training on pacing during $20-\mathrm{km}$ cycling time trial. Appl. Physiol. Nutr. Metab. 42, 391-398. doi: 10.1139/apnm-2016-0072

De Pauw, K., Roelands, B., Cheung, S. S., De Geus, B., Rietjens, G., and Meeusen, R. (2013). Guidelines to classify subject groups in sport-science research. Int. J. Sports Physiol. Perform. 8, 111-122. doi: 10.1123/ijspp. 8.2.111

Garcia-Pallares, J., Garcia-Fernandez, M., Sanchez-Medina, L., and Izquierdo, M. (2010). Performance changes in world-class kayakers following two different training periodization models. Eur. J. Appl. Physiol. 110, 99-107. doi: 10.1007/ s00421-010-1484-9

Goutianos, G. (2016). Block periodization training of endurance athletes: a theoretical approach based on molecular biology. Cell Mol. Exerc. Physiol. 4:11. doi: $10.7457 / \mathrm{cmep} . v 4 i 2 . e 9$

Granata, C., Oliveira, R. S. F., Little, J. P., and Bishop, D. J. (2019). Forty high-intensity interval training sessions blunt exercise-induced changes in the nuclear protein content of PGC-1alpha and p53 in human skeletal muscle. Am. J. Physiol. Endocrinol. Metab. 318, E224-E236. doi: 10.1152/ ajpendo.00233.2019

Hayot, M., Michaud, A., Koechlin, C., Caron, M. A., Leblanc, P., Prefaut, C., et al. (2005). Skeletal muscle microbiopsy: a validation study of a minimally invasive technique. Eur. Respir. J. 25, 431-440. doi: 10.1183/09031936.05.00053404

Hellsten, Y., and Nyberg, M. (2015). Cardiovascular adaptations to exercise training. Compr. Physiol. 6, 1-32. doi: 10.1002/cphy.c140080
University College. The patients/participants provided their written informed consent to participate in this study.

\section{AUTHOR CONTRIBUTIONS}

NA, SE, ØS, BR, and KS contributed to conception and design of the study. NA, HE, MW, HH, SI, and KS executed the study, collected, and analyzed the data. NA and KS performed the statistical analysis and wrote the first draft of the manuscript. All authors contributed to manuscript revision, read, and approved the submitted version.

\section{ACKNOWLEDGMENTS}

The authors kindly thank Anne-Kristine Meinild Lundby and Lise Koll for their exquisite work in the laboratory on the skeletal muscle analyses.

Issurin, V. B. (2010). New horizons for the methodology and physiology of training periodization. Sports Med. 40, 189-206. doi: 10.2165/11319770-00000000000000

Issurin, V. B. (2019). Biological background of block periodized endurance training: a review. Sports Med. 49, 31-39. doi: 10.1007/s40279018-1019-9

Jones, A. M. (2006). The physiology of the world record holder for the women's marathon. Int. J. Sports Sci. Coach. 1, 101-116. doi: 10.1260/174795406 777641258

Manzi, V., Iellamo, F., Impellizzeri, F., D’ottavio, S., and Castagna, C. (2009). Relation between individualized training impulses and performance in distance runners. Med. Sci. Sports Exerc. 41, 2090-2096. doi: 10.1249/ MSS.0b013e3181a6a959

Mccall, G. E., Byrnes, W. C., Dickinson, A. L., and Fleck, S. J. (1998). Sample size required for the accurate determination of fiber area and capillarity of human skeletal muscle. Can. J. Appl. Physiol. 23, 594-599. doi: 10.1139/ h98-034

Mcgawley, K., Juudas, E., Kazior, Z., Strom, K., Blomstrand, E., Hansson, O., et al. (2017). No additional benefits of block-over evenly-distributed highintensity interval training within a polarized microcycle. Front. Physiol. 8:413. doi: 10.3389/fphys.2017.00413

Molmen, K. S., Ofsteng, S. J., and Ronnestad, B. R. (2019). Block periodization of endurance training - a systematic review and meta-analysis. Open Access J. Sports Med. 10, 145-160. doi: 10.2147/OAJSM.S180408

Mujika, I., Halson, S., Burke, L. M., Balague, G., and Farrow, D. (2018). An integrated, multifactorial approach to periodization for optimal performance in individual and team sports. Int. J. Sports Physiol. Perform. 13, 538-561. doi: 10.1123 /ijspp.2018-0093

Peronnet, F., and Massicotte, D. (1991). Table of nonprotein respiratory quotientan update. Can. J. Sport Sci. 16, 23-29.

Perry, C. G., Lally, J., Holloway, G. P., Heigenhauser, G. J., Bonen, A., and Spriet, L. L. (2010). Repeated transient mRNA bursts precede increases in transcriptional and mitochondrial proteins during training in human skeletal muscle. J. Physiol. 588, 4795-4810. doi: 10.1113/jphysiol. 2010.199448

Psilander, N., Wang, L., Westergren, J., Tonkonogi, M., and Sahlin, K. (2010). Mitochondrial gene expression in elite cyclists: effects of high-intensity interval exercise. Eur. J. Appl. Physiol. 110, 597-606. doi: 10.1007/ s00421-010-1544-1

Ronnestad, B. R., Ellefsen, S., Nygaard, H., Zacharoff, E. E., Vikmoen, O., Hansen, J., et al. (2014). Effects of 12 weeks of block periodization on performance and performance indices in well-trained cyclists. Scand. J. Med. Sci. Sports 24, 327-335. doi: 10.1111/sms.12016 
Ronnestad, B. R., Hansen, J., and Ellefsen, S. (2012). Block periodization of high-intensity aerobic intervals provides superior training effects in trained cyclists. Scand. J. Med. Sci. Sports 24, 34-42. doi: 10.1111/j.1600-0838. 2012.01485.x

Ronnestad, B. R., Hansen, J., Thyli, V., Bakken, T. A., and Sandbakk, O. (2016). 5 -week block periodization increases aerobic power in elite cross-country skiers. Scand. J. Med. Sci. Sports 26, 140-146. doi: 10.1111/sms.12418

Seiler, S. (2010). What is best practice for training intensity and duration distribution in endurance athletes? Int. J. Sports Physiol. Perform. 5, 276-291. doi: 10.1123 /ijspp.5.3.276

Siebenmann, C., Cathomen, A., Hug, M., Keiser, S., Lundby, A. K., Hilty, M. P., et al. (2015). Hemoglobin mass and intravascular volume kinetics during and after exposure to 3,454-m altitude. J. Appl. Physiol. 119, 1194-1201. doi: 10.1152/japplphysiol.01121.2014

Siebenmann, C., Robach, P., Jacobs, R. A., Rasmussen, P., Nordsborg, N., Diaz, V., et al. (2012). "Live high-train low" using normobaric hypoxia: a double-blinded, placebo-controlled study. J. Appl. Physiol. 112, 106-117. doi: 10.1152/japplphysiol.00388.2011

Solli, G. S., Tonnessen, E., and Sandbakk, O. (2019). Block vs. traditional periodization of HIT: two different paths to success for the world's best cross-country skier. Front. Physiol. 10:375. doi: 10.3389/fphys.2019.00375

Stoggl, T., and Sperlich, B. (2014). Polarized training has greater impact on key endurance variables than threshold, high intensity, or high volume training. Front. Physiol. 5:33. doi: 10.3389/fphys.2014. 00033

Van Erp, T., Sanders, D., and De Koning, J. J. (2019). Training characteristics of male and female professional road cyclists: a 4-year retrospective analysis. Int. J. Sports Physiol. Perform. 5, 1-7. doi: 10.1123/ijspp.2019-0320

Conflict of Interest: The authors declare that the research was conducted in the absence of any commercial or financial relationships that could be construed as a potential conflict of interest.

Publisher's Note: All claims expressed in this article are solely those of the authors and do not necessarily represent those of their affiliated organizations, or those of the publisher, the editors and the reviewers. Any product that may be evaluated in this article, or claim that may be made by its manufacturer, is not guaranteed or endorsed by the publisher.

Copyright (c) 2022 Almquist, Eriksen, Wilhelmsen, Hamarsland, Ing, Ellefsen, Sandbakk, Rønnestad and Skovereng. This is an open-access article distributed under the terms of the Creative Commons Attribution License (CC BY). The use, distribution or reproduction in other forums is permitted, provided the original author(s) and the copyright owner(s) are credited and that the original publication in this journal is cited, in accordance with accepted academic practice. No use, distribution or reproduction is permitted which does not comply with these terms. 